\title{
Deterioração físico-conservacionista da microbacia hidrográfica do riacho Paus Brancos, Campina Grande, PB ${ }^{1}$
}

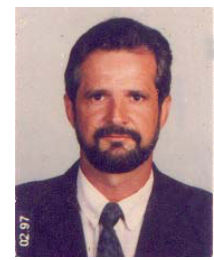

José G. de V. Baracuhy², Silvia M. de J. M. Kurtz ${ }^{3}$, Fabio C. Kurtz ${ }^{3}$, Simone M. A. Duarte ${ }^{4}$, Vera L. A. de Lima ${ }^{5}$, José S. M. da Rocha ${ }^{6} \&$ José Dantas Neto

\footnotetext{
${ }_{1}^{1}$ Parte da Tese de Doutorado do primeiro autor, financiada pelo BNB e ABEAS

2 UFCG/CCT/DEAg. Av. Pedro II 434, CEP 58109-270, Campina Grande, PB. Fone: (83) 342-0029. E-mail: abeascg@terra.com.br (Foto)

${ }^{3}$ UFSM/DER/CCR. CEP 97105-060, Santa Maria, RS. Fone: (55) 220-8261 E-mail: kurtz@ccr.ufsm.br

${ }^{4}$ Eng. Agrícola. CEP 58109-270, Campina Grande, PB. Fone: (83) 342-0029. E-mail: abeascg@terra.com.br

${ }^{5}$ UFCG/CCT/DEAg. CEP 58109-970, Campina Grande, PB. Fone: (83) 310-1318. E-mail: antunes@deag.ufpb.br

${ }^{6}$ UFSM/DER/CCR. CEP 97105-060, Santa Maria, RS. Fone: (55) 220-8261 E-mail: jsmrocha@terra.com.br

7 UFCG/CCT/DEAg. CEP 58109-970, Campina Grande, PB. Fone: (83) 310-1373. E-mail: zedantas@deag.ufpb.br
}

Protocolo 7 - 18/1/2002 - Aprovado em 15/4/2003

\begin{abstract}
Resumo: O presente trabalho foi realizado na microbacia do Riacho Paus Brancos, Campina Grande, PB, no semi-árido paraibano, e consistiu na realização do diagnóstico da deterioração físico-conservacionista. A microbacia, com uma área de 2.309,7 ha, foi dividida em 11 minibacias. A metodologia consistiu em determinar o coeficiente de rugosidade (RN) a partir das características físicas das minibacias e para a distribuição das classes de aptidão de uso da terra foi usado o coeficiente de rugosidade. Na microbacia estudada a deterioração físicoconservacionista é alta $(34,91 \%)$ contribuindo, para este valor, a pequena cobertura vegetal, 232,15 ha $(10,05 \%)$. Existem apenas 172,37 ha $(7,48 \%)$ em conflitos; no entanto, para a microbacia atingir seu equilíbrio ambiental, necessita ser trabalhada em $1.286,14$ ha $(55,68 \%)$ através de medidas prognosticadas por diagnósticos auxiliares. Nenhuma minibacia da Classe A apresentou excesso em área agrícola. A área deteriorada na microbacia é de 507,35 ha $(21,97 \%)$.
\end{abstract}

Palavras-chave: coeficiente de rugosidade, deterioração ambiental, semi-árido

\section{Physical conservationist deterioration of the microbasin of Paus Brancos stream, Campina Grande, PB, Brazil}

\begin{abstract}
The objective of the present study consisted in the diagnosis of the physical conservationist deterioration of the microbasin of the Paus Brancos Stream, Campina Grande, $\mathrm{PB}$, in the semi-arid region of Paraiba state. The microbasin was divided in 11 minibasin. The methodology consisted in determination of the rugosity coefficient (Ruggdeness Number RN), using the physical characteristics of the minibasins and the distribution of land use classes using the rugosity coefficient. In the studied area the physical conservationist deterioration is high $(34.91 \%)$, contributing to this the small vegetable covering 232.15 ha $(10.05 \%)$. There is availability of many areas for the agriculture but their utilization depends on auxiliary diagnosis. Although there are only 172.37 ha $(7.48 \%)$ in conflicts, for the perfect environmental equilibrium of the microbasin, 1,286.14 ha $(55.68 \%)$ need to be worked out. No class A minibasin presented excess of agricultural area. The deteriorated area in the studied microbasin is 507.35 ha $(21.97 \%)$.
\end{abstract}

Key words: rugosity coefficient, conflict environmental, semi-arid

\section{INTRODUÇÃO}

As regiões secas do Mundo, mais especificamente a região semi-árida do Nordeste brasileiro, estão seriamente ameaçadas de terem sua produtividade reduzida pelos intensos processos de deterioração. O problema agrava-se ainda pelo fato de ser o semi-árido do Nordeste brasileiro o mais populoso do mundo, com cerca de 1/3 da população nacional (Carvalho, 1998). A seca, apesar de estar relacionada com o fator climático dado à alta evaporação potencial da região em foco, $\left(2000 \mathrm{~mm} \mathrm{ano}^{-1}\right)$, quando associada aos processos de deterioração, tem seus efeitos danosos, com proporções insuportáveis, afetando diretamente a sobrevivência da população nordestina. (Carvalho, 1998). 
O uso de pequenas reservas de água em açudes, onde o espelho d'água não tem nenhuma proteção para a perda por evaporação, é um mecanismo pouco viável. Assim, o manejo de componentes ambientais que aumentem a infiltração de água no solo, procedente da precipitação atmosférica, passa a ser um caminho para abastecer/reabastecer barragens, coletando a água precipitada. Trabalhos técnicos têm demonstrado que uma área florestada aumenta, até próximo de $100 \%$, a quantidade de água infiltrada, procedente da chuva (Rocha, 1997).

O diagnóstico conservacionista para avaliar a deterioração ambiental deve ser a primeira fase na elaboração de um planejamento para uma bacia, sub-bacia ou microbacia hidrográfica. Nele são usadas técnicas de quantificação de retenção de água das chuvas, por infiltração, associada a vários fatores correlatos, tais como: limpeza de canais e tributários, seleção de terras apropriadas para o florestamento, faixas de contenção e controle de áreas agrícolas e pastoris envolvendo ainda todos os processos de conservação do solo (Rocha \& Kurts, 2001).

Segundo Rowntree (1990) a bacia hidrográfica oferece exelente estrutura para manejo e planejamento dos recursos hídricos, integrando-se com o desenvolvimento de políticas ambientais, sociais e econômicas e muitos modelos têm sido utilizados neste manejo integrado, como o desenvolvido por Hollingwort \& Mullins (1995) na bacia hidrográfica do Rio Sabie, África do Sul. Por outro lado, Duda \& El-Ashry (2000) afirmam que, apesar do termo "manejo integrado de bacias" ter sido idealizado como solução para problemas das bacias hidrográficas, muitos resultados têm sido desapontantes desde que ações de uso do solo e de biodiversidade não se têm integrado com as atividades dos setores de recursos hídricos.

Tyson (1995) relata que em regiões onde os recursos solo e água são escassos, regiões áridas e semi-áridas, por exemplo, o manejo integrado de bacias hidrográficas é essencial devido à complexidade das interações entre esses recursos. No Brasil, conforme afirma Baracuhy (2001), a complexidade do manejo de bacias hidrográficas é reconhecida até por Lei Federal $\left(\mathrm{n}^{\mathrm{o}}\right.$ 9.433 de 8/1/1997), onde o próprio Estado reconhece a necessidade de participação da sociedade, inclusive na avaliação das diversidades físicas, bióticas, demográficas econômicas, sociais e culturais.

Rocha \& Kurtz (2001) afirmam que, tecnicamente, é aconselhável começar a recuperar a ambiência adotando-se, como unidade básica, as bacias hidrográficas, as quais, subdivididas em sub-bacias e microbacias, têm mostrado grande eficiência em trabalhos de campo.

Para se manter a ambiência equilibrada, Morais (1997) sugere uma metodologia para o diagnóstico da situação real em que se encontram os recursos naturais renováveis, em um espaço geográfico, passa a ser um instrumento necessário em um trabalho de conservação.

Rocha \& Kurts (2001) comentam que, de acordo com os diagnósticos são elaborados prognósticos que são indicadores para a melhoria de vida dos habitantes da área em estudo. $\mathrm{O}$ diagnóstico é realizado com o objetivo de se conhecer os problemas que afetam uma população, através de observações, questionamentos, análises e interpretações dos recursos naturais renováveis com relação à qualidade de vida. $\mathrm{O}$ prognóstico é a previsão ou a suposição sobre o que deve acontecer em uma comunidade se esta se submeter às recomendações técnicas de melhoria de vida, as quais são formuladas pela interpretação dos diagnósticos.
Para amenizar as perdas dos recursos naturais foi criado pelo Ministério da Agricultura, em 1987, um programa em nível nacional, denominado de Programa Nacional de Microbacias Hidrográficas (PNMH) o qual tinha, como meta, a implantação de 1.000 microbacias hidrográficas durante o ano de 1987 e mais 3.000 nos anos subseqüentes (1988-1990) priorizando áreas com predominância de pequenas propriedades rurais, com o objetivo de introduzir um novo padrão de desenvolvimento rural, visando o uso e manejo adequado do solo com a preservação dos recursos naturais e melhoria das condições de vida nas comunidades rurais e urbanas (Brasil, 1987).

Para Lepsch et al. (1983) os recursos naturais, assim como o capital e o trabalho, constituem os fatores essenciais da produção em qualquer exploração econômica. O solo é o principal recurso natural para o aproveitamento agrícola, porém esgotável, conforme o processo aplicado na sua exploração e a forma de atuação do homem ao explorá-lo, ganha importância à medida que aumentam a necessidade e a intensidade de exploração.

Segundo Mello Filho (1992), os conflitos de uso da terra podem acontecer em duas situações: quando o tipo de uso da terra contraria a destinação recomendada a partir do coeficiente de rugosidade $(\mathrm{RN})$, ou quando o uso da terra, mesmo que coincida com o indicado pelo coeficiente de rugosidade, subestime o potencial da terra, com baixa produtividade, por técnicas inadequadas, ineficientes ou condenáveis. O coeficiente de rugosidade direciona a atividade de agricultura, pecuária ou florestamento ou, ainda, preservação florestal, de acordo com o uso potencial da terra.

Pereira Filho (1986) afirmou que capacidade de uso da terra e RN se equivalem em 99,9\% dos casos e, assim, propôs que se substitua a capacidade de uso da terra pelo RN, que é um método mais rápido e sem necessidade de coleta de amostras no campo, facilitando principalmente, o aspecto econômico.

Dentro dessa concepção, faz-se necessário a criação de unidades de conservação de uso direto e indireto no semi-árido nordestino, que introduzam o manejo da bacia hidrográfica como forma de assegurar a proteção florestal em seus amplos aspectos.

O objetivo do presente trabalho consistiu em realizar o diagnóstico da deterioração conservacionista da microbacia do Riacho Paus Brancos, Campina Grande, PB, como subsídio técnico a partir do qual possam ser tomadas decisões práticas para se manter equilibrada a ambiência da microbacia.

\section{MATERIAL E MÉTODOS}

A área estudada foi a microbacia hidrográfica de assentamento do povoado de Paus Brancos, município de Campina Grande no Estado da Paraíba. Sua localização geográfica fica entre as coordenadas: $7^{\circ} 25^{\prime} 00^{\prime \prime}$ de latitude Sul e $35^{\circ} 30^{\prime} 00^{\prime \prime}$ de longitude Oeste. A microbacia apresenta área total de 2.309,70 ha e para análise do diagnóstico físico-conservacionista, baseado nos divisores de água, foi subdividida em 11 minibacias respeitando-se seus acidentes e configuração geomorfológicas. A metodologia tradicional consiste em efetuar o diagnóstico físico-conservacionista em sub-bacias hidrográficas divididas em microbacias; todavia, em se tratando de uma área experimental-piloto inferior a 20.000 ha (conforme preconizado na metodologia tradicional - Rocha \& Kurts, 2001) adotou-se a sistemática de denominar a unidade maior como microbacia, com respectivas subdivisões em minibacias. 
O relevo da região varia de suavemente plano a ondulado. Os tipos de solo encontrados na microbacia em estudo são: Luvissolos, Planossolos, Vertissolos, Neossolos e Cambissolo conforme classificação apresentada por EMBRAPA (1999)

A metodologia aplicada ao diagnóstico físico-conservacionista da microbacia hidrográfica em estudo encontra-se detalhada em Baracuhy (2001). O Coeficiente de Rugosidade (Ruggdeness Number - RN) foi determinado multiplicando-se a declividade média da minibacia pelo valor numérico da densidade de drenagem, em que:

$$
\begin{gathered}
\mathrm{RN}=\mathrm{HD} \\
\mathrm{H}=\frac{\sum \mathrm{ccn} \Delta \mathrm{h}}{\mathrm{S}} \\
\mathrm{D}=\frac{\sum \mathrm{ca}}{\mathrm{S}}
\end{gathered}
$$

em que:

H - declividade média

D - densidade de drenagem

$\Sigma$ ccn - somatório dos comprimentos das curvas de nível

$\Sigma$ ca - somatório dos comprimentos dos afluentes (ravinas, canais e tributários)

$\Delta \mathrm{h} \quad$ - eqüidistância das curvas de nível $(\Delta \mathrm{h}=10 \mathrm{~m})$

$\mathrm{S} \quad$ - área da minibacia

O RN é um parâmetro que direciona o uso potencial da terra com relação às suas características para agricultura, pecuária ou florestamento. As classes de RN são de quatro tipos tradicionais, conforme Tabela 1 (Rocha, 1997).

Para distribuição das classes de aptidão de uso das terras, tomaram-se por base os valores de RN encontrados, ordenan-

Tabela 1. Avaliação das classes de aptidão de uso das terras

\begin{tabular}{cc}
\hline Tipos de Classe de RN & Terras Propícias \\
\hline A & Agricultura \\
B & Pastagem \\
C & Pastagem/Florestamento \\
D & Florestamento \\
\hline
\end{tabular}

do-se de forma crescente; posteriormente calculou-se a amplitude (RN maior - RN menor) e o intervalo (amplitude dividida por quatro) desses coeficientes de rugosidade.

As unidades críticas de deterioração físico-conservacionista foram determinadas a partir da equação da reta, utilizando-se os valores mínimos e máximos e o valor modal significativo encontrado. A deterioração pode variar de zero a $100 \%$, assim se:

$$
\begin{gathered}
Y=a x+b \\
a x^{\prime}+b=0 \\
a x^{\prime \prime}+b=100
\end{gathered}
$$

em que:

Y - unidade crítica de deterioração, \%

$\mathrm{x}$ - valor modal encontrado a partir da Tabela 2

x' e x" - valores mínimos e máximos respectivamente a e b - coeficientes da equação da reta

Tabela 2. Valores modais* dos parâmetros do diagnóstico físicoconservacionista em função das classes de estratificação

\begin{tabular}{ccc}
$\begin{array}{c}\text { Classe de Estratificação } \\
(\%)\end{array}$ & $\begin{array}{c}\text { C, AF, EAA, AST, DU } \\
\text { (Valor Modal) }\end{array}$ & $\begin{array}{c}\text { CF, DAA } \\
\text { (Valor Modal) }\end{array}$ \\
\hline $0-10$ & 1 & 10 \\
$11-20$ & 2 & 9 \\
$21-30$ & 3 & 8 \\
$31-40$ & 4 & 7 \\
$41-50$ & 5 & 6 \\
$51-60$ & 6 & 5 \\
$61-70$ & 7 & 4 \\
$71-80$ & 8 & 3 \\
$81-90$ & 9 & 2 \\
$91-100$ & 10 & 1 \\
\hline *C - Conflitos; AF - Àrea a florestar; EAA - Excesso em área para a agricultura; AST - Área a ser \\
trabalhada; DU - Deterioração da unidade; CF - Cobertura florestal; DAA - Disponibilidade de água \\
para a agricultura
\end{tabular}

\section{RESULTADOS E DISCUSSÃO}

\begin{tabular}{|c|c|c|c|c|c|c|c|}
\hline $\begin{array}{c}\text { Mini } \\
\text { Bacias }\end{array}$ & $\begin{array}{l}\text { Área } \\
\text { (ha) }\end{array}$ & $\begin{array}{c}\Sigma \mathrm{ca} \\
(\mathrm{km})\end{array}$ & $\begin{array}{l}\sum \mathrm{ccn} \\
(\mathrm{hm})\end{array}$ & $\begin{array}{l}\text { Declividade } \\
\left(\mathrm{m} \mathrm{m}^{-1}\right)\end{array}$ & $\begin{array}{c}\mathrm{D} \\
\left(\mathrm{km} \mathrm{ha}^{-1}\right)\end{array}$ & $\mathrm{RN} 10^{-5}$ & $\begin{array}{c}\text { Classes de } \\
\text { RN }\end{array}$ \\
\hline 1 & 339,92 & 5,68 & 60,02 & 0,0177 & 0,0167 & 29,51 & A \\
\hline 2 & 388,03 & 8,20 & 54,93 & 0,0142 & 0,0211 & 29,92 & A \\
\hline 3 & 144,35 & 3,04 & 37,67 & 0,0261 & 0,0211 & 55,01 & A \\
\hline 4 & 205,30 & 4,24 & 64,64 & 0,0315 & 0,0206 & 64,97 & A \\
\hline 5 & 167,48 & 4,79 & 44,71 & 0,0267 & 0,0286 & 76,32 & A \\
\hline 6 & 217,55 & 3,43 & 138,21 & 0,0635 & 0,0158 & 100,15 & B \\
\hline 7 & 124,19 & 3,89 & 40,57 & 0,0327 & 0,0314 & 102,42 & B \\
\hline 8 & 203,36 & 6,31 & 67,17 & 0,0330 & 0,0310 & 102,43 & B \\
\hline 9 & 206,25 & 5,33 & 82,83 & 0,0402 & 0,0258 & 100,75 & B \\
\hline 10 & 142,13 & 6,24 & 53,29 & 0,0375 & 0,0439 & 164,69 & $\mathrm{C}$ \\
\hline 11 & 171,14 & 8,79 & 96,81 & 0,0566 & 0,0158 & 290,47 & $\mathrm{D}$ \\
\hline
\end{tabular}

As características físicas das minibacias do Riacho Paus Brancos e as respectivas classes de RN encontram-se na Tabela 3. Quanto ao comportamento da declividade média por minibacia, constata-se que as minibacias 6 e 11 são as mais

Tabela 3. Características* físicas das minibacias da microbacia do Riacho Paus Brancos e classes de RN

Área total da Microbacia do Riacho Paus Brancos $=2.309,70$ ha

\footnotetext{
* $\Sigma$ ca - Somatório do comprimento dos afluentes (ravinas, canais e tributários); $\Sigma$ ccn - Somatório do comprimento das curvas de nível; D - densidade de drenagem; RN - coeficiente de rugosidade
} 
declivosas enquanto 1 e 2 são as mais planas. Tal estudo se fez necessário para se conseguir informações auxiliares na locação de área (coroas de proteção) de nascentes para cada minibacia. De modo idêntico, a Tabela 3 retrata o comportamento das ravinas, canais e tributários definindo o $\mathrm{RN}$ por minibacia; neste caso, observa-se um comprimento maior de escoamento superficial nas minibacias 11 e 2, nas quais deve-se concentrar provavelmente, os processos de captação de água das chuvas. A energia do relevo mostrou-se mais acentuada nas minibacias 6 e 11, onde obteve-se maiores valores para as curvas de forma. A declividade e RN são componentes básicos para a determinação do coeficiente de rugosidade de cada minibacia.

Na Tabela 3, a classe A (vocação agrícola) abrange as minibacias $1,2,3,4,5$ e 6, a classe $\mathrm{B}$ (vocação para pecuária) as minibacias 7, 8 e 9, enquanto a classe a $\mathrm{C}$ (vocação florestamento/pecuária) compreende somente a minibacia 10 , e a classe $\mathrm{D}$ (vocação para florestamento) domina a minibacia 11 , sendo o coeficiente de rugosidade (uso potencial da terra) definido pelo produto da declividade média da minibacia pelo valor numérico da densidade de drenagem. Observa-se que, realmente, o maior produto entre a densidade de drenagem e a declividade média se encontra na minibacia 11.

Segundo Rocha (1997), para as minibacias da classe A se a declividade média $(\mathrm{H})$ for maior que 0,10 é necessário que se façam tratos conservacionistas. Em minibacias com declividade média de até 0,15 o florestamento mínimo necessário é de $25 \%$ e, se a declividade média for maior de que 0,15 , o florestamento mínimo será de $50 \%$.

A Tabela 4 mostra o uso da terra por minibacia na microbacia hidrográfica do Riacho Paus Brancos. Observa-se predominância das áreas de pastagens sobre os demais usos da terra. Nota-se que o termo pastagem abrangeu todas as áreas que não foram ocupadas por agricultura ou florestamentos. Neste tema foram incluídas vegetações herbáceas, gramináceas, áreas desnudas, bem como áreas erodidas, potencialmente indicadas para pastagem e /ou florestamento. Há de se considerar que, na maior parte do ano nas regiões semi-áridas, "as pastagens" tem pouco valor econômico.

Ainda com relação a ocupação espacial do uso da terra, pode-se observar, na Tabela 4 que: as minibacias 9,1 e 6 apresentam maior cobertura florestal e as minibacias 10 e 3 são as mais desprovidas de vegetação; as minibacias 2 e 1 apresentam maiores áreas de campo (pastagem) sendo aí incluídas terras desnudas e erodidas; as áreas com ocupação

Tabela 4. Uso da terra (ha) por minibacia

\begin{tabular}{crrccc}
\hline Minibacia & Florestas & Pastagens & $\begin{array}{c}\text { Cultivos } \\
\text { Agrícolas }\end{array}$ & $\begin{array}{c}\text { Áreas } \\
\text { Construídas }\end{array}$ & $\begin{array}{c}\text { Espelho } \\
\text { de Água }\end{array}$ \\
\hline 1 & 43,96 & 287,33 & 8,54 & 0,09 & - \\
2 & 13,74 & 366,27 & 8,01 & 0,01 & - \\
3 & 4,90 & 138,34 & 1,09 & 0,02 & - \\
4 & 31,25 & 174,04 & - & 0,01 & - \\
5 & 18,85 & 148,60 & - & 0,03 & - \\
6 & 35,17 & 181,00 & - & - & 1,38 \\
7 & 7,03 & 117,07 & - & 0,06 & 0,03 \\
8 & 5,30 & 198,03 & - & 0,03 & - \\
9 & 56,65 & 147,92 & - & 0,08 & 1,60 \\
10 & 1,85 & 125,01 & 15,17 & 0,04 & 0,06 \\
11 & 13,45 & 153,01 & 4,62 & 0,06 & - \\
\hline Total & 232,15 & 2036,62 & 37,43 & 0,43 & 3,07 \\
\hline
\end{tabular}

agrícola (agricultura de subsistência) ocorreram nas minibacias 10, 1, 2, 11 e 3, em ordem de grandeza; a área agrícola (37,43 ha) corresponde a apenas $1,62 \%$ da área da microbacia, como a agricultura ainda é o único meio de sobrevivência da população local, este pequeno percentual de área agrícola evidencia o estado de pobreza absoluta em que se encontra os moradores da região.

Uma das características típicas das microbacias do semi-árido nordestino, pequena quantidade de espelho de água, também foi observada na microbacia estudada. A maioria das minibacias não apresenta nenhum tipo de espelho de água. O total encontrado 3,07 ha, é resultado da computação de algumas pequenas barragens e açudes encontrados nas áreas, principalmente nas minibacias 6 e 9. Quanto à área construída, praticamente se resume à construção das casas dos moradores da região.

A Figura 1 mostra a ocorrência dos principais usos da terra na microbacia estudada: áreas de pastagens, vegetação arbustiva e arbórea e áreas cultivadas. Obviamente, a maior ocupação refere-se à área de pastagem. Na microbacia estudada observa-se uma agricultura pouco intensiva e, quando ocorre, é exclusivamente de subsistência, e foi evidenciada principalmente nas minibacias 1, 2, 3, 10 e 11, com maior destaque para a minibacia 10 .

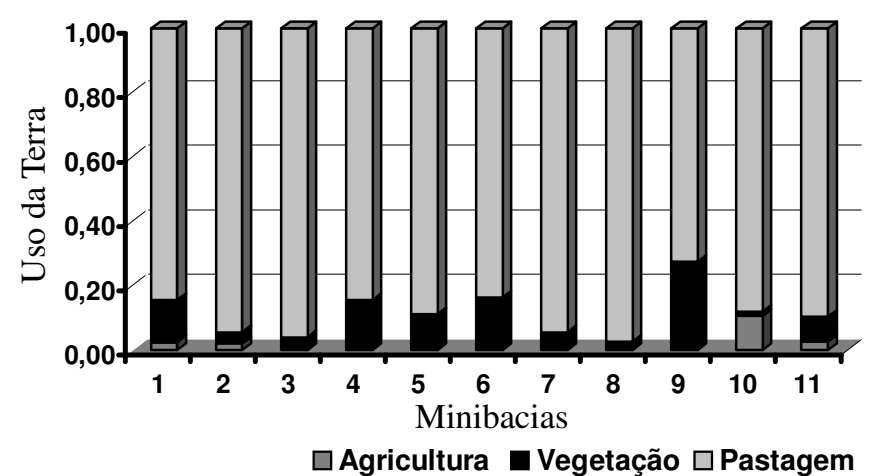

Figura 1. Principais ocupações do uso da terra, por minibacia

O termo vegetação engloba florestas de pequeno e médio porte, respectivamente, pequena e média densidade e vegetação de renques, exemplares estes sobreviventes de uma devastação tradicional na região, para o consumo energético.

A Tabela 5 retrata os conflitos existentes na microbacia hidrográfica do Riacho Paus Brancos e em cada minibacia. Considerando-se que todas as minibacias possuem declividades médias inferiores a 0,1 (Tabela 3 ) os conflitos só ocorreriam nas minibacias de classes $\mathrm{C}$ e $\mathrm{D}$, com qualquer tipo de agricultura ou associação, bem como aquelas deterioradas.

Verifica-se que a minibacia 10, que possui uma área de 142,13 ha, apresentou 15,17 ha de conflitos $(10,67 \%)$. Para as minibacias de classe D os conflitos, ocorrem com a existência de agricultura, associações, queimadas ou pastagens. No caso presente a minibacia 11 apresentou 157,63 ha de conflito; portanto, um conflito correspondente a $92,11 \%$ da respectiva minibacia; neste caso, o elemento responsável pelo conflito foi a área semidesnuda, classificada como pastagem. Em toda a área da microbacia $(2309,70$ ha) o conflito físico ambiental ocorreu em 172,80 ha, correspondendo a 7,48\% da mesma. 
Tabela 5. Conflitos ${ }^{1}$ por minibacia

\begin{tabular}{|c|c|c|c|c|c|c|c|c|}
\hline \multirow{2}{*}{$\begin{array}{l}\text { Mini } \\
\text { Bacias }\end{array}$} & \multirow{2}{*}{$\begin{array}{c}\text { Vegetação } \\
(\%)\end{array}$} & \multirow{2}{*}{$\begin{array}{c}\text { C } \\
\text { (ha) }\end{array}$} & \multirow{2}{*}{$\begin{array}{l}\mathrm{AF} \\
\text { (ha) }\end{array}$} & \multirow{2}{*}{$\begin{array}{l}\mathrm{D} / \mathrm{E} \\
\text { (ha) }\end{array}$} & \multirow{2}{*}{$\begin{array}{l}\text { AT } \\
\text { (ha) }\end{array}$} & \multicolumn{2}{|c|}{$\mathrm{AD}$} & \multirow{2}{*}{$P$} \\
\hline & & & & & & (ha) & $(\%)$ & \\
\hline 1 & 12,93 & - & 41,03 & $-246,31$ & 287,33 & 41,03 & 12,07 & 8 \\
\hline 2 & 3,54 & - & 83,27 & $-283,00$ & 366,27 & 83,27 & 21,46 & 5 \\
\hline 3 & 3,39 & - & 31,19 & $-107,15$ & 138,34 & 31,19 & 21,62 & 4 \\
\hline 4 & 15,22 & - & 20,08 & $-153,96$ & 174,04 & 20,08 & 9,78 & 9 \\
\hline 5 & 11,25 & - & 23,03 & $-125,57$ & 148,60 & 23,03 & 13,75 & 7 \\
\hline 6 & 16,17 & - & 19,21 & 0,00 & 18,21 & 19,21 & 8,83 & 10 \\
\hline 7 & 5,66 & - & 24,02 & 0,00 & 24,02 & 24,02 & 19,34 & 6 \\
\hline 8 & 2,61 & - & 45,53 & 0,00 & 45,53 & 45,03 & 22,39 & 3 \\
\hline 9 & 27,47 & - & 0,00 & 0,00 & 0,00 & 0,00 & 0,00 & 11 \\
\hline 10 & 1,30 & 15,17 & 33,68 & $+15,17$ & 33,68 & 48,85 & 34,37 & 2 \\
\hline 11 & 7,86 & 157,63 & 29,33 & $+4,62$ & 29,33 & 171,14 & 100,00 & 1 \\
\hline Total & 9,76 & 172,80 & 350,37 & - & 1286,14 & 507,35 & 21,97 & - \\
\hline
\end{tabular}

1 - C - conflitos; AF - área a florestar; AT - área a trabalhar; D/E - Disponibilidade e/ou excesso em agricultura (-Disponível , +Excesso); AD - Área deteriorada; P - prioridades

Em virtude da pequena cobertura florestal da microbacia $(10,05 \%)$, cada minibacia apresenta defasagem muito grande com relação aos números preconizados para um bom manejo integrado de microbacia hidrográfica; assim é que, com exceção da minibacia 9 , que tem cobertura florestal superior a $25 \%$ (mínimo necessário para minibacias com declividade abaixo de 15\%, segundo Rocha, 1997), demais minibacias necessitam de grandes percentuais de florestamentos, perfazendo um total de 350,37 ha, o que corresponde a $15,17 \%$ da microbacia. No presente caso, as minibacias 2 e 8 são as mais desprovidas de cobertura florestal e, portanto, por serem mais susceptíveis às erosões, necessitam maiores florestamentos.

Nenhuma minibacia da classe A apresentou excesso em área agrícola, especialmente pelo fato da inexistência de uma agricultura de caráter comercial. Não obstante o pequeno uso agrícola na região, as minibacias 1, 2, 3, 4 e 5 apresentam grandes áreas com disponibilidade para os cultivos agrícolas próprios da região. Por outro lado, as minibacias 6, 7,8 e 9 não apresentaram disponibilidade nem excesso em agricultura. As minibacias 10 e 11, por serem classificadas como classe C e $\mathrm{D}$, próprias apenas para pastagem e florestamento, apresentam áreas em excesso para os cultivos agrícolas.

Com relação às minibacias de aptidão agrícola (minibacia 1 de Classe A), no presente caso não se encontrou áreas em excesso agrícola. Para as minibacias de classes B, C e D (terras propícias, respectivamente, à pecuária, pecuária/florestamento e florestamento) as áreas a serem trabalhadas foram consideradas somente como áreas a florestar e áreas em disponibilidade para agricultura.

Observa-se, ainda, na Tabela 5, que a maior ação antrópica de recuperação ambiental encontra-se nas minibacias 2 e 1, 366,27 e 287,33 ha, respectivamente, que, apesar de não apresentarem conflito ambiental, necessitam de maior recuperação, visto que foram mais desgastadas pela própria ação antrópica com impactos negativos. Percentualmente (Figura 2), as áreas com maior ação antrópica de recuperação ambiental encontramse nas minibacias 3 e 2, com 95,84 e $94,39 \%$, respectivamente; apenas a minibacia 9 não necessita de trabalho de recuperação. Para as minibacias 6, 7, 8 e 9 de classes B (terras propícias para pecuária), as áreas a serem trabalhadas foram consideradas como áreas a florestar enquanto que as minibacias $\mathrm{Ce} D$ (terras propícias, respectivamente, à pecuária/florestamento $\mathrm{e}$ florestamento) as áreas a serem trabalhadas foram consideras aquelas em disponibilidade para agricultura.

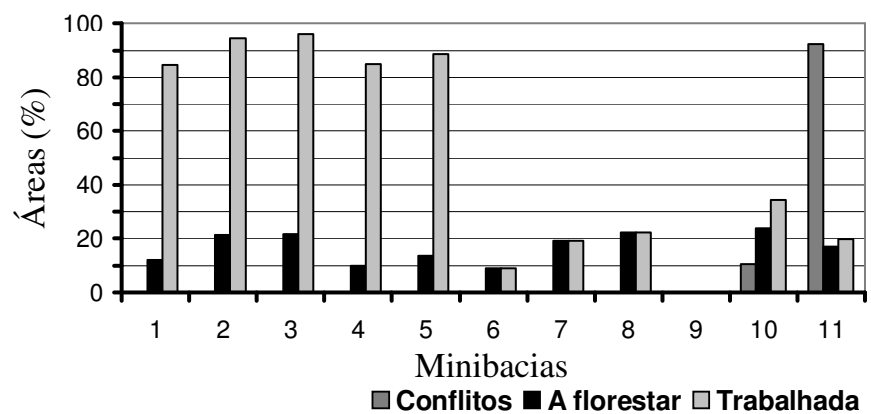

Figura 2. Áreas em conflitos físicos ambientais, a serem florestadas e trabalhadas por minibacias

As deteriorações de cada minibacia (Tabela 5) foram avaliadas levando-se em consideração as áreas de conflitos e as áreas a florestar. No presente caso, as minibacias com maiores áreas deterioradas foram as 11 e 2 com 176,14 e 83,27 ha, respectivamente, enquanto a minibacia 9 não apresentou deterioração ambiental Os percentuais de deterioração por minibacia retrata a prioridade do manejo integrado, parte físico-conservacionista, cujos valores são opostos às percentagens de áreas deterioradas como, por exemplo, a minibacia 11 , que está $100 \%$ deteriorada e tem prioridade 1 ; já a minibacia 9 , que não tem deterioração, apresenta prioridade 11 (última prioridade).

A deterioração conservacionista por fator e total na microbacia hidrográfica do Riacho Paus Brancos, é apresentada na Tabela 6 e na Figura 3. Observa-se, nesta tabela, que os fatores conflitos e excesso para agricultura apresentaram valores modais corresponde ao valor mínimo atribuído o que, segundo o mesmo, não proporciona deterioração físico-conservacionista na microbacia estudada.

No outro extremo, o fator cobertura florestal apresentou um valor modal igual ao valor máximo significativo, proporcionando deterioração máxima (100\%). Como um todo, a microbacia Paus Brancos apresentou o valor $34,91 \%$ de unidades críticas de deterioração físico-conservacionista. Apesar dos pequenos conflitos na microbacia, a deterioração encontrada mostra que a cobertura florestal é baixa e a área a ser trabalhada para o manejo correto da unidade é muito grande. Rocha (1997) encontrou, para a sub-bacia hidrográfica do Rio Passo fundo, RS, uma deterioração físico-conservacionista da ordem de $87,25 \%$. 
Tabela 6. Unidades críticas de deterioração física conservacionista da microbacia Paus Brancos

\begin{tabular}{|c|c|c|c|c|c|}
\hline \multirow{2}{*}{ Fator } & \multicolumn{3}{|c|}{ Valores Significativos } & \multirow{2}{*}{ Equação da Reta } & \multirow{2}{*}{ Deterioração (\%) } \\
\hline & Mínimo & Máximo & Moda & & \\
\hline Conflitos & 1 & 10 & 1 & $\mathrm{Y}=11,111 \mathrm{X}-11,111$ & 0,00 \\
\hline Cobertura florestal & 1 & 10 & 10 & $\mathrm{Y}=11,111 \mathrm{X}-11,111$ & 100,00 \\
\hline Área a florestar & 1 & 10 & 2 & $\mathrm{Y}=11,111 \mathrm{X}-11,111$ & 11,11 \\
\hline Disponibilidade para agricultura & 1 & 10 & 6 & $\mathrm{Y}=11,111 \mathrm{X}-11,111$ & 55,55 \\
\hline Excesso para a agricultura & 1 & 10 & 1 & $\mathrm{Y}=11,111 \mathrm{X}-11,111$ & 0,00 \\
\hline Área a ser trabalhada & 1 & 10 & 6 & $\mathrm{Y}=11,111 \mathrm{X}-11,111$ & 55,55 \\
\hline Deterioração da unidade & 1 & 10 & 3 & $\mathrm{Y}=11,111 \mathrm{X}-11,111$ & 22,22 \\
\hline Total & 7 & 70 & 29 & $\mathrm{Y}=1,587 \mathrm{X}-11,111$ & 34,91 \\
\hline
\end{tabular}

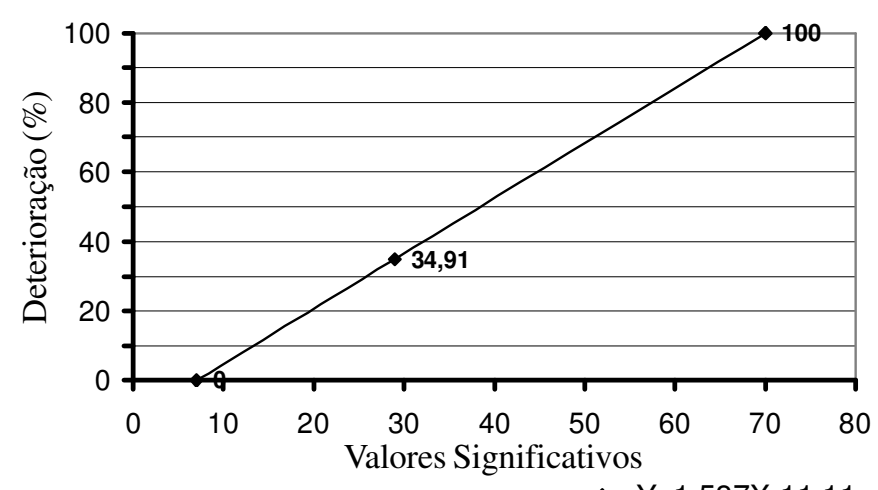

Figura 3. Reta de deterioração físico-conservacionista da microbacia Paus Brancos

\section{CONCLUSÕES}

1. Na microbacia hidrográfica do riacho Paus Brancos a deterioração físico-conservacionista é alta $(34,91 \%)$, contribuindo para este valor a pequena cobertura vegetal de 232,15 ha.

2. Dentro da microbacia, apenas as minibacias das classes $\mathrm{C}$ e D, apresentaram excesso em área agrícola.

3. Há disponibilidade de áreas para a agricultura, porém seu aproveitamento depende das medidas prognosticadas por diagnósticos auxiliares.

4. Apesar de existir apenas 172,37 ha em conflitos, a microbacia, para ter o seu equilíbrio ambiental adequado, necessita ser trabalhada em 1.286,14 ha. A área deteriorada na área estudada é de 507,35 ha.

5. Deveram ser florestadas todas as áreas e coroas de proteção de nascentes em cada minibacia.

\section{LITERATURA CITADA}

Baracuhy, J.G.V. Manejo integrado de microbacias no semiárido nordestino: estudo de um caso. Campina Grande: UFPB, 2001. 221p. Tese Doutorado
Brasil. Ministério da Agricultura. Comissão Nacional de Coordenação do PNMH. Programa Nacional de Microbacias Hidrográficas: Manual operativo. Brasília: Ministério da Agricultura, 1987.60p.

Carvalho, O. A economia política do Nordeste: secas, irrigação e desenvolvimento. Rio de Janeiro: Editora Campus. 1998. $197 \mathrm{p}$.

Duda, A.M.; El-Ashry, M.T. Addressing the global water and environmental crisis through integrated management of land, water and ecological resources. Water International, Washington, v.25, n.1, p.115-126. 2000.

EMBRAPA - Empresa Brasileira de Pesquisa Agropecuária. Centro Nacional de Pesquisa de Solos. Sistema brasileiro de classificação de solos. Brasília. EMBRAPA, 1999. 412p.

Hollingwort, B.; Mullins, D. Economic analysis of water resource development proposals in the Sabir River Basin. Water Science and Tecnology, London, v.32, n.5-6, p.71-78, 1995.

Lepsch, I. F., Bellinazzi Jr., R. Bertolini, D. Manual para levantamento utilitário do meio físico e classificação de terras no sistema de capacidade de uso. Campinas: Sociedade Brasileira de Ciências do Solo, 1983. 175p.

Mello Filho, J.A. Direcionamento da ocupação da terra, pelo diagnóstico físico-conservacionista, das microbacias hidrográficas dos rios Alambari e Sesmaria, em Resende, RJ. Santa Maria: UFSM, 1992. 50p. Monografia Especialização

Morais, S.M.J. Diagnósticos quantitativos mínimos de ambiência para o manejo integrado da sub-bacia hidrográfica do arroio Cadena: Santa Maria: UFSM, 1997. 135p. Dissertação Mestrado

Pereira Filho, W. Capacidade de uso da terra em função do coeficiente de rugosidade. Santa Maria: UFSM, 1986. 48p. Monografia Especialização

Rocha, J. S. M. da. Manual de projetos ambientais. Santa Maria: UFSM, 1997.423p.

Rocha, J.S.M. da; Kurts, S.M.J.M. Manual de manejo integrado de bacias hidrográficas. 4 ed. Santa Maria: UFSM/CCR, 2001. 120p.

Rowntree, K. Political and administrative constraints on integrated river basin development: an evaluation of the Tana and Athi Rivers. Applied Geography, Chicago, v.10. n.1, p.21-41, 1990.

Tyson, J.M. Quo vadis - sustainability? Water Science and Technology, London, v.32, n.5-6, p.1-5.1995. 